\title{
Perancangan Fotobioreaktor Mikroalga Chlorella vulgaris untuk Mengoptimalkan Kosentrasi Oksigen $\left(\mathrm{O}_{2}\right)$
}

\author{
Nadya Okta Biolita*, Harmadi \\ Laboratorium Elektronika dan Instrumentasi, Jurusan Fisika FMIPA \\ Universitas Andalas, Kampus Unand, Limau Manis, Padang, 25163 \\ "nadyaoktabiolita@gmail.com
}

\begin{abstract}
ABSTRAK
Telah dilakukan perancangan fotobioreaktor mikroalga Chlorella vulgaris untuk mengoptimalkan konsentrasi Oksigen $\left(\mathrm{O}_{2}\right)$ menggunakan sumber cahaya dari lampu halogen dan LED biru. Pada perancangan ini digunakan cahaya matahari sebagai pembanding dari sumber cahaya buatan dan cahaya dengan intensitas 0 lux untuk kontrol perlakuan pada ruangan gelap. Sistem dilengkapi dengan alat kontrol temperatur menggunakan dua sensor LM35. Fotobioreaktor memiliki dua tabung, masingmasing tabung berisi $1250 \mathrm{ml}$ mikroalga Chlorella vulgaris. Tabung pertama disuplai gas $\mathrm{CO}_{2}$ dengan kecepatan alir 0,5 L/min dan tabung kedua tidak disuplai gas $\mathrm{CO}_{2}$. Intensitas sumber cahaya lampu halogen divariasikan pada 1000, 3000 dan 5000 lux. Intensitas LED biru yang digunakan adalah 1065 lux. Pengontrolan temperatur berhasil mempertahankan temperatur fotobioreaktor pada rentang $25-35$ ${ }^{\circ} \mathrm{C}$. Konsentrasi maksimum gas $\mathrm{O}_{2}$ yang dihasilkan yaitu $21,7 \%$ pada fotobioreaktor yang menggunakan lampu halogen 1000 lux dengan suplai gas $\mathrm{CO}_{2}$ dengan lama penyinaran 7 jam. Hasil ini sesuai dengan fotobioreaktor menggunakan sumber cahaya matahari dengan suplai gas $\mathrm{CO}_{2}$ pada jam $15.00 \mathrm{WIB}$. Kata kunci: fotobioreaktor, lampu halogen, LED biru, LM35, mikroalga Chlorella vulgaris.
\end{abstract}

\section{ABSTRACT}

Microalgae Chlorella vulgaris photobioreactor to optimize the concentration of Oxygen $\left(\mathrm{O}_{2}\right)$ using halogen lamp and Blue LED has been designed. In this design, sunlight is used as comparison to artificial light source and light with intensity of 0 lux for treatment control in dark room. The system is equipped with a temperature control device using two LM35 sensors. Photobioreactor has two tubes, each tube contains $1250 \mathrm{ml}$ of Chlorella vulgaris microalgae. The first tube is supplied with $\mathrm{CO}_{2}$ gas with a flow rate of $0.5 \mathrm{~L} / \mathrm{min}$ and the second tube is not supplied with $\mathrm{CO}_{2}$ gas. The intensity of the halogen lamp light source is varied at 1000, 3000 and 5000 lux. The intensity of blue LED used is 1065 lux. Temperature control successfully maintains the photobioreactor temperature in the range of $25-35^{\circ} \mathrm{C}$. The maximum concentration of $\mathrm{O}_{2}$ gas produced is $21.7 \%$ in the photobioreactor using a 1000 lux halogen lamp with a $\mathrm{CO}_{2}$ gas supply with 7 hours of exposure time. This result is in accordance with the photobioreactor using a solar light source with a $\mathrm{CO}_{2}$ gas supply at 03.00 PM.

Keywords: blue LED, halogen lamp, LM35, microalgae chlorella vulgaris, photobioreactor.

\section{PENDAHULUAN}

Pemanasan global dapat menyebabkan meningkatnya temperatur di permukaan bumi, sehingga berpotensi menimbulkan bencana alam. Salah satu penyebab dari pemanasan global adalah bertambahnya emisi gas $\mathrm{CO}_{2}$ (Karbondioksida). $\mathrm{Gas} \mathrm{CO}_{2}$ merupakan emisi terbesar yang dilepaskan ke udara pada kasus pembakaran hutan, konsentrasi gas $\mathrm{CO}_{2}$ mencapai $90 \%$ dari emisi keseluruhan pembakaran (Nurhayati dkk., 2010). Pertambahan emisi gas $\mathrm{CO}_{2}$ sangat mempengaruhi kualitas udara. Usaha untuk mengurangi konsentrasi gas $\mathrm{CO}_{2}$ telah banyak dilakukan, salah satunya dengan menggunakan mikroalga. Mikroalga memiliki jumlah yang berlimpah dan perkembang biakannya cukup mudah untuk dilakukan sehingga mikroalga mampu menjadi sumber daya yang terbaharukan (Daniyati dkk., 2012). Mikroalga menangkap $\mathrm{CO}_{2}$ bersama cahaya untuk proses fotosintesis sehingga menghasilkan $\mathrm{O}_{2}$. (Pujiono, 2013). Salah satu jenis mikroalga yang paling banyak dimanfaatkan untuk mitigasi emisi gas $\mathrm{CO}_{2}$ adalah Chlorella vulgaris. Chlorella vulgaris mudah ditemukan hampir di seluruh wilayah Indonesia. Chlorella vulgaris mampu berfotosintesis dengan sumber cahaya buatan (Bernard dkk., 2016) memiliki umur sel yang lebih lama dibandingkan dengan mikroalga lainnya yaitu mencapai 60 hari (Kurnia, 2015). Pengoptimalan kemampuan dari mikroalga dalam menangkap konsentrasi $\mathrm{O}_{2}$ dapat diperoleh melalui perancangan suatu fotobioreaktor. Salah satu jenis fotobioreaktor adalah fotobioreaktor tubullar yang memiliki efisiensi fotosintesis tertinggi dibandingkan dengan jenis fotobioreaktor tertutup lainnya (Hadiyanto dkk., 2012). Penggunaan 
fotobioreaktor pada mikroalga untuk pengoptimalan konsentrasi $\mathrm{O}_{2}$ dan mitigasi emisi gas $\mathrm{CO}_{2}$ telah dikembangkan oleh Santoso dkk. (2011), Daniyati dkk. (2012) dan Yuliandri dkk. (2013). Penelitian Daniyati dkk. (2012) tidak memvariasikan sumber cahaya pada fotobioreaktor. Fotobireaktor yang dirancang oleh Santoso dkk. (2011) dan Yuliandri dkk. (2013) tidak mengukur konsentrasi gas $\mathrm{O}_{2}$ dan tidak memvariasikan sumber cahaya.

Penelitian ini merancang fotobioreaktor mikroalga Chlorella vulgaris untuk mengoptimalkan kosentrasi $\mathrm{O}_{2}$. Fotobioreaktor yang dirancang adalah fotobioreaktor tubullar dengan variasi pemberian konsentrasi gas $\mathrm{CO}_{2}$ sebesar $0,5 \mathrm{~L} / \mathrm{min}$ dan tanpa pemberian konsentrasi gas $\mathrm{CO}_{2}$. Fotobioreaktor ini menggunakan mikroalga Chlorella vulgaris dan sumber cahaya berasal dari LED biru dan lampu halogen. Konsentrasi $\mathrm{O}_{2}$ yang dihasilkan kemudian dibandingkan dengan yang dihasilkan sumber cahaya matahari dan kontrol perlakuan pada keadaan tanpa cahaya. Suhu fotobioreaktor dikontrol dengan alat kontrol temperatur. Pengontrolan suhu dilakukan karena mikroalga mampu hidup secara maksimal pada rentang suhu 25 - $35^{\circ} \mathrm{C}$ (Chrismada dkk., 2007).

\section{METODE}

\subsection{Penelitian Pendahuluan}

Penelitian pendahuluan yang dilakukan meliputi pembuatan nutrien pada mikroalga, pengujian respon konsentrasi $\mathrm{O}_{2}$ pada mikroalga, pengkulturan awal mikroalga Chlorella vulgaris sebanyak $250 \mathrm{~mL}$ dan pengujian absorbsi cahaya mikroalga Chlorella vulgaris menggunakan spektrometer UV-Vis.

\subsubsection{Pembuatan nutrien pada mikroalga}

Pembuatan nutrien ini menggunakan metode Bold Bassal Medium (BBM). Metode ini menggunakan 15 jenis nutrien, 11 nutrien $\left(\mathrm{K}_{2} \mathrm{HPO}_{4}\right.$ (Dikalium fosfat), $\mathrm{KH}_{2} \mathrm{PO}_{4}$ (Kalium dihidrogen fosfat), $\mathrm{MgSO}_{4} \cdot 7 \mathrm{H}_{2} \mathrm{O}$ (Garam inggris), $\mathrm{NaNO}_{3}$ (Natrium nitrat), $\mathrm{CaCl}_{2} \cdot 2 \mathrm{H}_{2} \mathrm{O}$ (Kalsium klorida), $\mathrm{Co}\left(\mathrm{NO}_{3}\right)_{2} \cdot 6 \mathrm{H}_{2} \mathrm{O}, \mathrm{CuSO}_{4} \cdot 5 \mathrm{H}_{2} \mathrm{O}, \mathrm{ZnSO}_{4} \cdot 7 \mathrm{H}_{2} \mathrm{O}, \mathrm{MnCl}_{2} \cdot 4 \mathrm{H}_{2} \mathrm{O}$ (Mangan (II) klorida tetrahidrat), $\mathrm{H}_{2} \mathrm{SO}_{4}$ (Asam sulfat), $\mathrm{NaCl}$ (Natrium klorida)) masing-masing nutrien diberi volume $10 \mathrm{~mL} .3$ nutrien $\left(\mathrm{FeSO}_{4} \cdot 7 \mathrm{H}_{2} \mathrm{O}, \mathrm{KOH}\right.$, EDTA) bervolume $1 \mathrm{~mL}$ dan $\mathrm{H}_{2} \mathrm{BO}_{3}$ bervolume $0,7 \mathrm{~mL}$. Masing-masing nutrien dari dilarutkan dengan aquades hingga $1000 \mathrm{~mL}$.

\subsubsection{Pengujian respon kosentrasi $\mathrm{O}_{2}$ pada sampel mikroalga $250 \mathrm{~mL}$}

Pengujian sampel mikroalga $250 \mathrm{ml}$ dilakukan untuk menentukan respon $\mathrm{O}_{2}$ yang terkandung. Penelitian dilakukan dengan cara pendeteksian $\mathrm{O}_{2}$ pada botol kultur mikroalga dan pada udara bebas seperti pada Gambar 1. Dari Gambar 1 dapat diketahui bahwa pada udara bebas konsentrasi $\mathrm{O}_{2}$ sebesar $19 \%$ dan pada botol kultur mikroalga konsentrasi $\mathrm{O}_{2}$ 19,1\%. Konsentrasi bertambah sebesar $0,1 \%$.

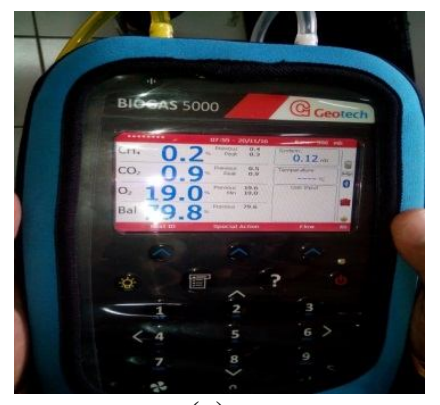

(a)

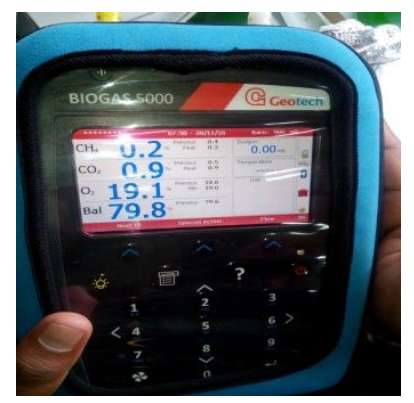

(b)

Gambar 1 Respon $\mathrm{O}_{2}$ pada (a) udara bebas dan (b) pada botol kultur mikroalga

\subsubsection{Pengkulturan awal mikroalga Chlorella vulgaris $250 \mathrm{ml}$}

Pengkulturan mikroalga Chlorella vulgaris dilakukan menggunakan nutrien yang telah dibuat, pemudian dicampurkan dengan bibit mikroalga sebanyak $17 \mathrm{~mL}$. 


\subsubsection{Pengujian absorbsi cahaya mikroalga Chlorella vulgaris menggunakan spektrometer} UV-Vis

Pengujian absorbsi cahaya dilakukan untuk mengetahui panjang gelombang yang mampu diserap oleh mikroalga. Dari pengujian diketahui bahwa panjang gelombang yang diserap oleh mikroalga berkisar antara $400 \mathrm{~nm}-700 \mathrm{~nm}$, hal ini menjadi alasan dari pemilihan LED Biru yang memiliki panjang gelombang $450 \mathrm{~nm}-500 \mathrm{~nm}$. Panjang gelombang maksimum yang diserap oleh mikroalga adalah $450 \mathrm{~nm}$ seperti yang ditunjukkan pada Gambar 2.

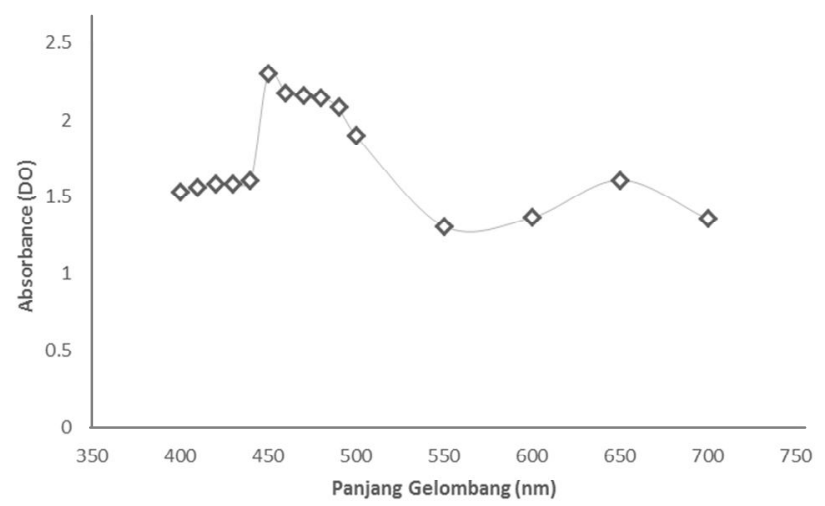

Gambar 2 Grafik Spektrometer UV-Vis untuk mikroalga Chlorella vulgaris

\subsection{Perancangan Alat Kontrol Temperatur}

Perancangan alat kontrol temperatur dilakukan untuk menjaga temperatur pada mikroalga yang berada pada rentang $25-35{ }^{\circ} \mathrm{C}$. Kontrol temperatur menggunakan dua buah sensor LM35, dimana sensor pertama (T1) digunakan pada fotobioreaktor yang di suplai gas $\mathrm{CO}_{2}$ dan dan sensor kedua (T2) digunakan pada fotobioreaktor tanpa suplai gas $\mathrm{CO}_{2}$. Kontrol temperatur ini menggunakan kipas dan heater untuk menjaga temperatur pada mikroalga. Hasil keluaran pada kontrol temperatur ini ditampilkan pada LCD 16 x 2 dan menggunakan Arduino Uno sebagai pengolah data.

\subsubsection{Perancangan Diagram Blok Sistem}

Perancangan sistem kontrol temperatur pada fotobioreaktor terdiri dari 2 rangkaian sensor tempertur (LM35), rangkaian sistem minimum mikrokontroller Arduino Uno, rangkaian LCD dan relai. Diagram blok dari perancangan sistem tersebut dapat dilihat pada Gambar 3.

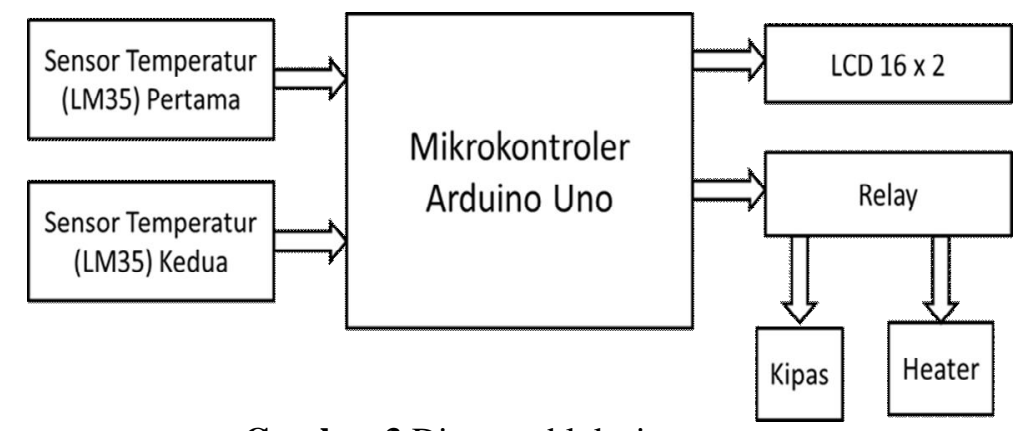

Gambar 3 Diagram blok sistem

Prinsip kerja dari pengontrolan temperatur pada penelitian ini yaitu diawali oleh masukan temperatur yang terbaca atau terdeteksi pada 2 rangkaian sensor LM35, selanjutnya mikrokontroler memproses nilai temperatur yang terdeteksi tersebut. Apabila salah satu temperatur yang terdeteksi lebih besar dari batas temperatur yang ditentukan $\left(\mathrm{T}>35^{\circ} \mathrm{C}\right)$, maka mikrokontroler mengaktifkan relai pada kipas dan menonaktifkan relai pada heater sehingga kipas menyala dan heater mati. Apabila salah satu temperatur yang terdeteksi lebih kecil dari batas temperatur yang ditentukan $\left(\mathrm{T}<25{ }^{\circ} \mathrm{C}\right)$ maka mikrokontroler menonaktifkan relai pada kipas dan mengaktifkan relai pada heater sehingga kipas mati heater menyala. 


\subsubsection{Perancangan Program}

Kontrol temperatur menggunakan 2 sensor LM35 dimana (T1) sebagai temperatur yang terukur pada fotobioreaktor yang disuplai gas $\mathrm{CO}_{2}$ dan (T2) sebagai temperatur yang terukur pada fotobioreaktor tanpa suplai gas $\mathrm{CO}_{2}$. Program yang dirancang berdasarkan pada diagram alir seperti pada Gambar 4. Pada awal program diberi input dari 2 sensor temperatur kemudian program membaca nilai temperatur yang terbaca pada 2 sensor LM35. Nilai input temperatur yang terdeteksi dibandingkan, heater akan menyala jika temperatur yang terukur di bawah $25-35{ }^{\circ} \mathrm{C}$. Jika temperatur $25^{\circ} \mathrm{C}$ hingga di atas $35^{\circ} \mathrm{C}$ kipas menyala. Nilai temperatur ditampilkan pada LCD.

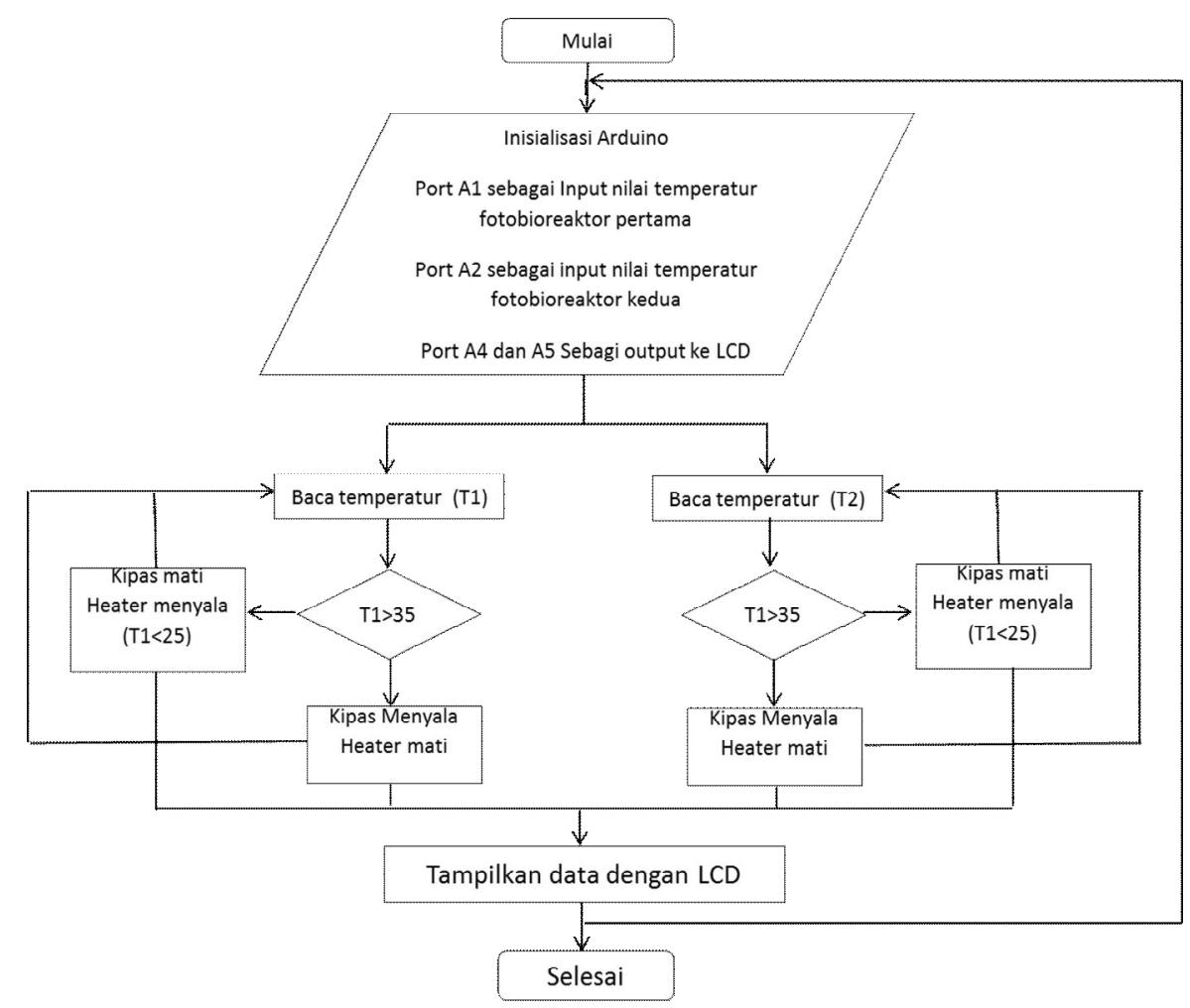

Gambar 4 Diagram alir program

\subsection{Perancangan Fotobioreaktor}

Perancangan menggunakan dua buah fotobioreaktor yang memiliki tinggi $50 \mathrm{~cm}$ dan berdiameter $10 \mathrm{~cm}$ yang diletakkan di dalam chamber cahaya berukuran $40 \mathrm{~cm}$ x $50 \mathrm{~cm}$ x 60 $\mathrm{cm}$. Masing - masing fotobioreaktor berisi $1250 \mathrm{~mL}$ mikroalga dengan pemberian mikroalga awal yaitu $250 \mathrm{~mL}$ dan pemberian nutrien sebanyak $1000 \mathrm{~mL}$

Salah satu fotobioreaktor disuplai dengan gas $\mathrm{CO}_{2}$ dengan kecepatan alir 0,5 L/min sementara fotobioreaktor yang lain tidak disuplai dengan $\mathrm{CO}_{2}$. Variasi pemberian $\mathrm{CO}_{2}$ ini dilakukan untuk mengetahui jenis fotobioreaktor yang paling baik dalam menghasilkan gas $\mathrm{O}_{2}$. Fotobioreaktor dilengkapi dengan alat kontol temperatur, alat kontrol ini mengatur temperatur fotobioreaktor agar tetap terjaga pada rentang $25-35{ }^{\circ} \mathrm{C}$. Keluaran gas $\mathrm{O}_{2}$ yang dihasilkan dari fotobioreaktor diukur menggunakan $\mathrm{O}_{2}$ gas analyzer. Perancangan dari fotobioreaktor ditunjukkan pada Gambar 5. 

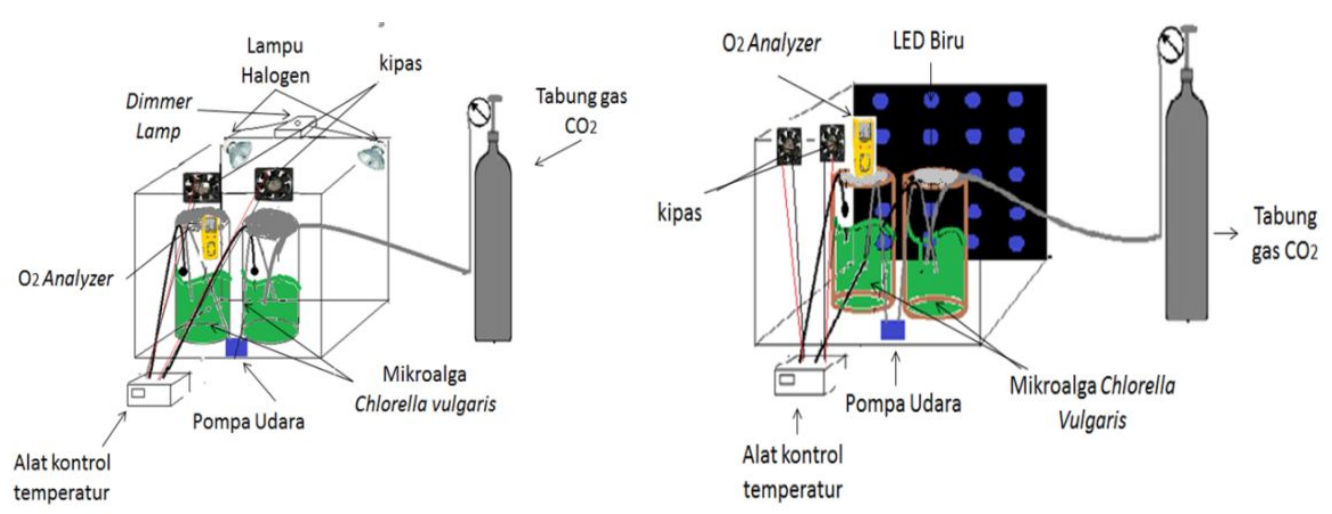

(a)

(b)

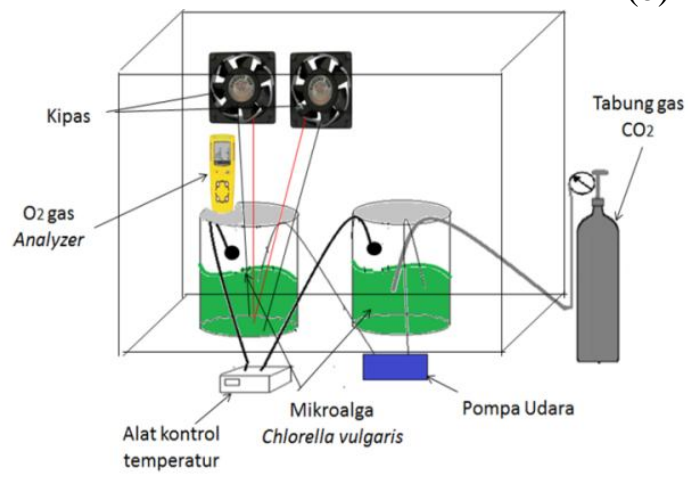

(c)

Gambar 5 Perancangan Fotobioreaktor (a) lampu halogen (b) LED Biru (c) cahaya matahari

Chamber cahaya dilapisi alumunium foil pada perancangan fotobioreaktor lampu halogen dan LED Biru, pada sumber cahaya matahari tidak dilapisi alumunium foil. Intensitas pada lampu halogen divariasikan sebesar 1000, 3000, dan 5000 lux, intensitas ini diatur menggunakan dimmer lamp. Selain ketiga perancangan diatas, dilakukan pengambilan data pada fotobioreaktor keadaan tanpa cahaya (0 lux). Perancangan fotobioreaktor yang digunakan sama seperti perancangan fotobioreaktor sumber cahaya matahari. Tujuan dari pengambilan data untuk keadaan tanpa cahaya (0 lux) adalah untuk mengetahui kemampuan mikroalga Chlorella vulgaris dalam menghasilkan konsentrasi $\mathrm{O}_{2}$ pada keadaan gelap. Pengambilan data pada perancangan fotobioreaktor lampu halogen, LED Biru, dan keadaan tanpa cahaya dilakukan selama 7 jam, sedangkan pada fotobioreaktor menggunakan sumber cahaya matahari dilakukan selama 10 jam.

\section{HASIL DAN DISKUSI}

\subsection{Karakterisasi Sensor LM35}

Karakterisasi dilakukan pada 2 sensor LM35. Hal ini dikarenakan alat kontrol temperatur digunakan untuk mengontrol temperatur pada 2 tabung Sensor LM35 ke-1 digunakan pada fotobioreaktor yang disuplai gas $\mathrm{CO}_{2}$ dan sensor LM35 ke-2 digunakan pada fotobioreaktor tanpa suplai gas $\mathrm{CO}_{2}$. Hasil karakterisasi sensor LM35 ke-1 dapat dilihat pada Gambar 6. 


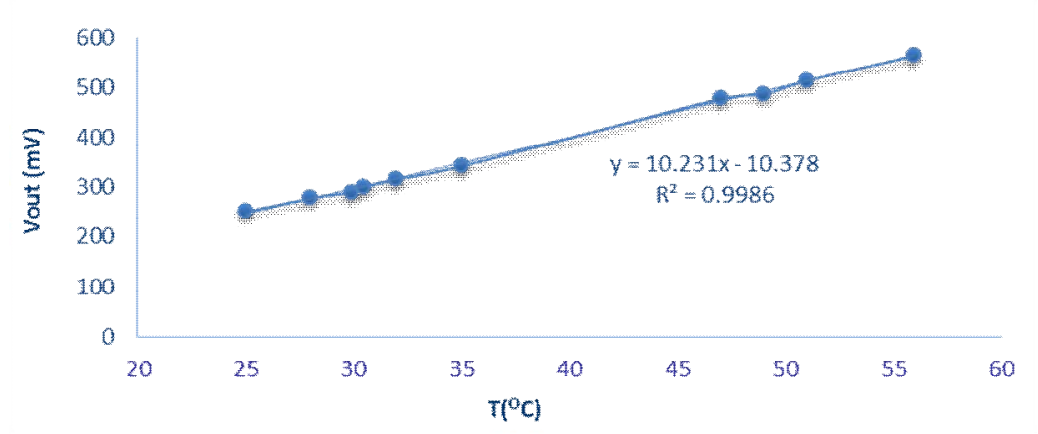

(a)

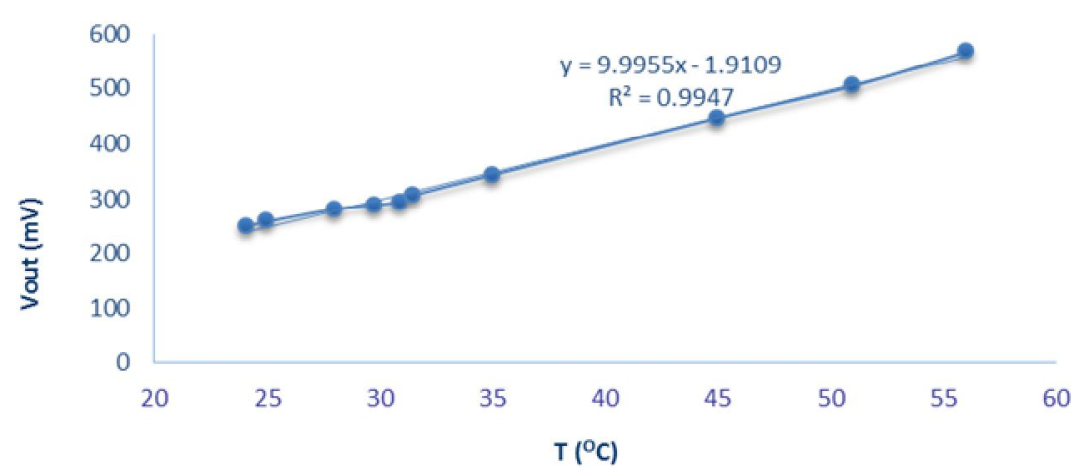

(b)

Gambar 6 Grafik hasil karakterisasi sensor LM35 (a) ke-1(b) ke-2

Pada Gambar 6 (a) didapatkan hasil karakterisasi sensor LM35 ke-1. Fungsi transfer yang didapatkan yaitu $y=10,231 x-10,378$. Fungsi transfer ini menunjukkan bahwa setiap perubahan temperatur sebesar $1{ }^{\circ} \mathrm{C}$ menghasilkan perubahan tegangan keluaran sebesar 10,231 $\mathrm{mV}$ dan memiliki tegangan offset sebesar $-10,378 \mathrm{mV}$. Nilai tegangan offset ini merupakan nilai tegangan awal sensor pada temperatur $0{ }^{\circ} \mathrm{C}$. Koefisien determinasi yang dihasilkan mendekati 1 yaitu sebesar 0,9986. Hasil karakterisasi sensor LM35 ke-2 menunjukkan fungsi transfer $y=$ $9,9955 x-1,9109$. Fungsi transfer ini menunjukkan bahwa setiap perubahan temperatur sebesar $1{ }^{\circ} \mathrm{C}$ menghasilkan perubahan tegangan keluaran sebesar $9,9955 \mathrm{mV}$ dan memiliki tegangan offset sebesar $-1,9109 \mathrm{mV}$. Nilai tegangan offset ini merupakan nilai tegangan awal sensor pada temperatur $0{ }^{\circ} \mathrm{C}$ bernilai $-1,9109 \mathrm{mV}$. Koefisien determinasi yang dihasilkan mendekati 1 yaitu sebesar 0,9947 .

\subsection{Pengukuran Alat Kontrol Temperatur}

Sistem kontrol ini menggunakan relai sebagai saklar. Sistem kontrol ini menjaga temperatur agar selalu pada rentang $25-35{ }^{\circ} \mathrm{C}$. Hasil pengujian dapat dilihat pada Gambar 7 . Pengujian temperatur dilakukan pada 2 sensor LM35. Saat sistem kontrol aktif maka sensor akan mendeteksi kenaikan temperatur hingga $35{ }^{\circ} \mathrm{C}$. Jika temperatur yang terdeteksi diatas 35 ${ }^{\circ} \mathrm{C}$ maka kipas aktif dan heater mati dan jika temperatur yang terdeteksi dibawah $25{ }^{\circ} \mathrm{C}$ maka heater akan menyala dan kipas mati. Sensor pertama, sistem kontrol ini dapat menjaga temperatur tertinggi $35,86{ }^{\circ} \mathrm{C}$ dan temperatur terendah yaitu $24,71{ }^{\circ} \mathrm{C}$. Sedangkan pada sensor kedua sistem kontrol ini dapat menjaga temperatur tertinggi sebesar $35,07{ }^{\circ} \mathrm{C}$ dan temperatur terendah yaitu $24,26{ }^{\circ} \mathrm{C}$. Perbedaan nilai temperatur yang terdeteksi oleh kedua sensor disebabkan oleh perbedaan nilai derajat kolerasi linier pada kedua sensor sehingga terjadinya perbedaan galat. 


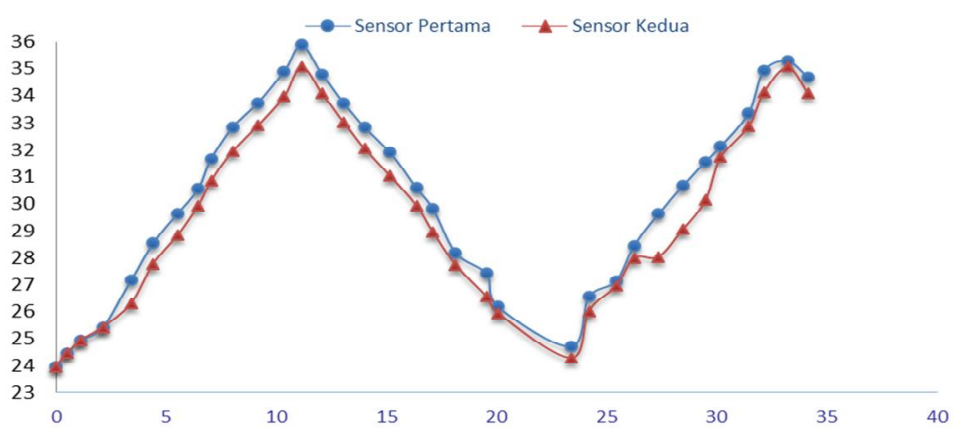

Gambar 7 Hasil pengujian kontrol temperatur

\subsection{Konsentrasi $\mathrm{O}_{2}$ pada Fotobioreaktor Sumber Cahaya Lampu Halogen}

Pengambilan data pada fotobioreaktor sumber cahaya lampu halogen dilakukan secara kontinyu pada intensitas cahaya 1000, 3000 dan 5000 lux sehingga terjadinya perbedaan waktu pada saat pengambilan data. Pengaturan intensitas cahaya lampu halogen menggunakan dimmer lamp. Hasil konsentrasi $\mathrm{O}_{2}$ yang dihasilkan ditunjukkan pada Gambar 8.

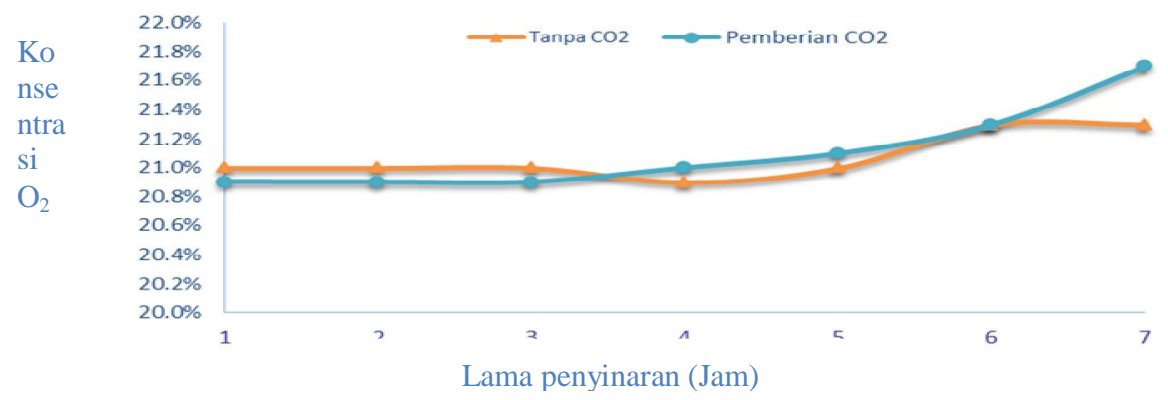

(a)

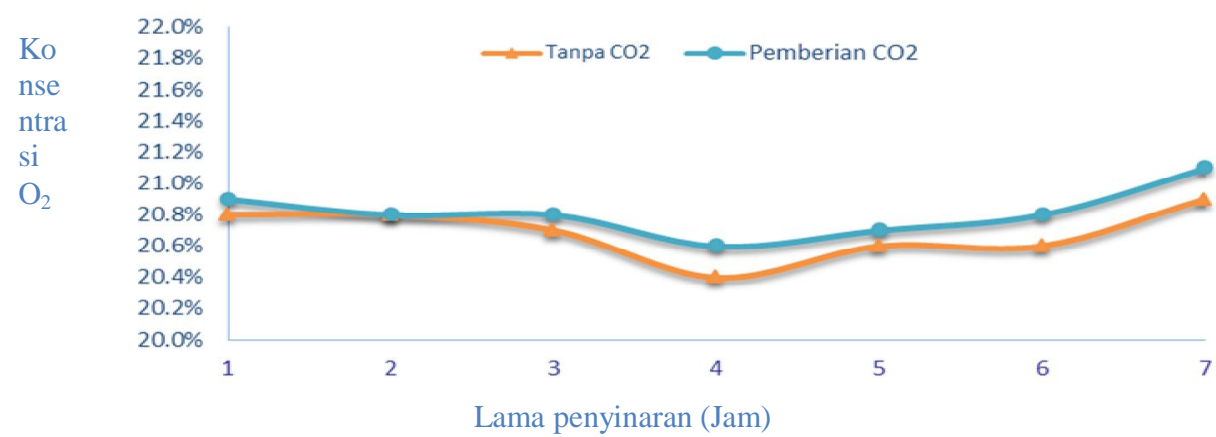

(b)

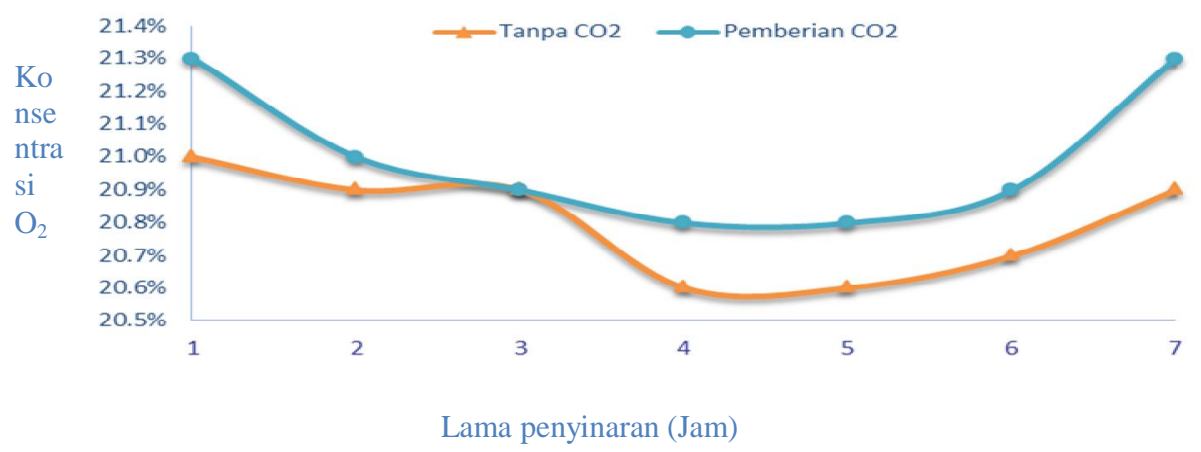

(c)

Gambar 8 Grafik konsentrasi gas $\mathrm{O}_{2}$ pada halogen (a) 1000 lux (b) 3000 lux (c) 5000 lux 
Waktu pengambilan data pada fotobioreaktor lampu halogen intensitas 1000 lux dilakukan dari jam 09.00 - 16.00 WIB. Pada intensitas 3000 lux dilakukan dari jam 16.00 23.00 WIB dan pada intensitas 5000 lux dilakukan pada jam 23.00 - 06.00 WIB. Pada fotobioreaktor sumber cahaya lampu halogen terjadi penurunan konsentrasi gas $\mathrm{O}_{2}$ yang signifikan pada jam ke-4. Hal ini membuktikan bahwa pada saat lama penyinaran 4 jam proses fotosintesis tidak berjalan dengan lancar dikarenakan terjadinya pengurangan energi yang dibutuhkan pada saat proses fotosintesis pada lama penyinaran tersebut. Andriyono (2001) menjelaskan bahwa periode penyinaran dapat berpengaruh dalam proses sintesis bahan organik pada fotosintesis karena hanya dengan energi yang cukup proses tersebut dapat berjalan dengan lancar.

Konsentrasi gas $\mathrm{O}_{2}$ paling tinggi dihasilkan pada fotobioreaktor sumber cahaya lampu halogen intensitas 1000 lux tanpa suplai gas $\mathrm{CO}_{2}$ yaitu sebesar $21,7 \%$. Perancangan fotobioreaktor lampu halogen menunjukkan bahwa konsentrasi gas $\mathrm{O}_{2}$ yang dihasikan pada fotobioreaktor dengan suplai gas $\mathrm{CO}_{2}$ lebih tinggi dibandingkan dengan tanpa suplai gas $\mathrm{CO}_{2}$. $\mathrm{Hal}$ ini dikarenakan suplai gas $\mathrm{CO}_{2}$ dibutuhkan dalam proses fotosintesis sehingga semakin tinggi pemberian gas $\mathrm{CO}_{2}$ maka konsentrasi gas $\mathrm{O}_{2}$ semakin tinggi.

\subsection{Konsentrasi $\mathrm{O}_{2}$ pada Fotobioreaktor Sumber Cahaya LED Biru}

Intensitas yang terukur pada fotobioreaktor LED Biru yaitu 1065 lux. Waktu pengambilan data dilakukan dari jam $13.00-20.00$ WIB. Hasil konsentrasi gas $\mathrm{O}_{2}$ yang didapatkan pada fotobioreaktor sumber cahaya LED biru dapat dilihat pada gambar 9. Gambar 9 menunjukkan konsentrasi $\mathrm{O}_{2}$ yang dihasilkan pada fotobioreaktor yang disuplai dengan gas $\mathrm{CO}_{2}$ dan tanpa suplai gas $\mathrm{CO}_{2}$ menggunakan LED biru. Pada kedua jenis fotobioreaktor ini terjadi kenaikan konsentrasi gas $\mathrm{O}_{2}$ pada jam ke - 4. Pada jam ke-5 hingga jam ke-7 konsentrasi gas $\mathrm{O}_{2}$ yang dihasilkan mikroalga Chlorella vulgaris mengalami penurunan.

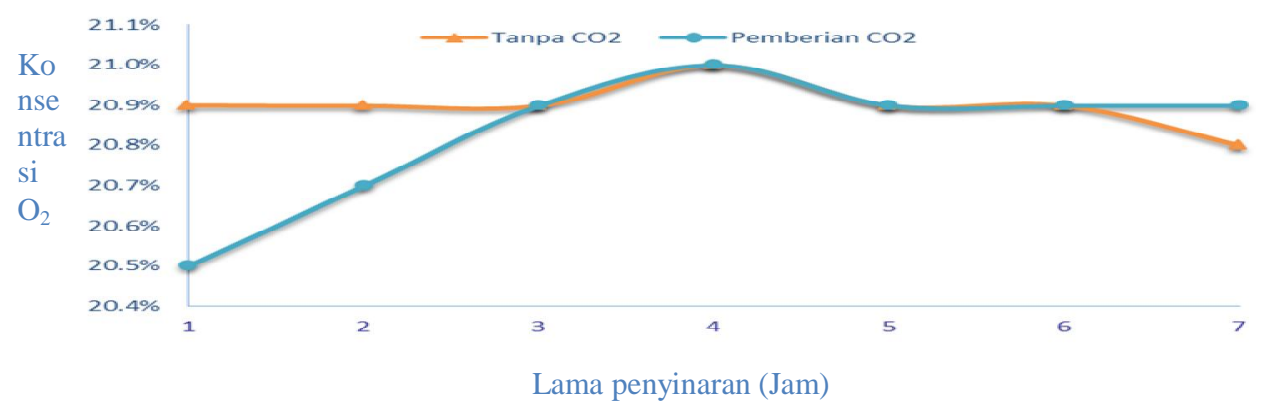

Gambar 9 Grafik konsentrasi gas $\mathrm{O}_{2}$ yang dihasilkan pada LED Biru

\subsection{Konsentrasi $\mathrm{O}_{2}$ pada Fotobioreaktor Sumber Cahaya Matahari}

Pengambilan data konsentrasi gas $\mathrm{O}_{2}$ pada perancangan fotobioreaktor menggunakan sumber cahaya matahari dilakukan dari jam 11.00 - 20.00 WIB. Intensitas cahaya yang terukur pada masing - masing jam berbeda - beda. Hasil konsentrasi gas $\mathrm{O}_{2}$ yang didapatkan pada fotobioreaktor sumber cahaya matahari dapat dilihat pada Gambar 10. 


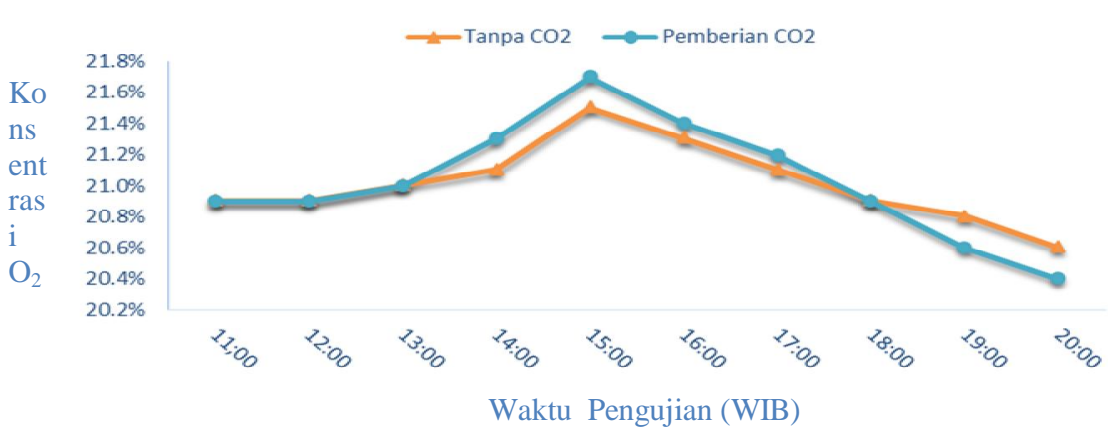

Gambar 10 Grafik konsentrasi gas $\mathrm{O}_{2}$ yang dihasilkan pada fotobioreaktor sumber cahaya matahari

Fotobioreaktor sumber cahaya matahari mengalami kenaikan konsentrasi gas $\mathrm{O}_{2}$ dari jam 11.00 - 15.00 WIB dan mengalami penurunan setelah jam 15.00- 20.00 WIB. Hal ini terjadi karena fotosintesis berlangsung optimal pada siang hari dan kemampuan mikroalga untuk melakukan fotosintesis akan berkurang dari sore hari hingga malam hari.

Pada jam 14.00 - 16. 00 WIB fotobioreaktor dengan suplai $\mathrm{CO}_{2}$ menghasilkan konsentrasi $\mathrm{O}_{2}$ lebih banyak jika dibandingkan dengan fotobioreaktor yang tidak disuplai dengan gas $\mathrm{CO}_{2}$. Hal ini membuktikan bahwa pada rentang waktu tersebut mikroalga Chlorella vulgaris dapat menyerap gas $\mathrm{CO}_{2}$ dengan sangat baik sehingga konsentrasi $\mathrm{O}_{2}$ pada fotobioreaktor dengan suplai $\mathrm{CO}_{2}$ menghasilkan konsentrasi gas $\mathrm{O}_{2}$ yang lebih banyak, sedangkan pada malam hari 19.00 - 20.00 WIB konsentrasi gas $\mathrm{O}_{2}$ yang dihasilkan pada fotobioreaktor tanpa suplai gas $\mathrm{CO}_{2}$ lebih banyak jika dibandingkan dengan fotobioreaktor yang diberikan suplai gas $\mathrm{CO}_{2}$. Hal ini dikarenakan kurangnya mikroalga dalam menyerap gas $\mathrm{CO}_{2}$ pada malam hari sehingga proses fotosintesis tidak berlangsung secara optimal dan menyebabkan terjadi emisi pada fotobioreaktor yang disuplai gas $\mathrm{CO}_{2}$ sehingga menyebabkan fotobioreaktor yang disuplai gas $\mathrm{CO}_{2}$ menghasilkan lebih sedikit konsentrasi gas oksigen $\left(\mathrm{O}_{2}\right)$.

Intensitas cahaya yang terukur pada perancangan fotobioreaktor ini memiliki intensitas yang berbeda-beda. Intensitas tertinggi adalah pada jam 14.00 WIB yaitu 53700 lux namun proses fotosintesis tidak berlangsung maksimal pada pada jam 14.00 WIB hal ini dikarenakan intensitas cahaya yang sangat tinggi dapat menjadikan terhambatnya proses fotosintesis (fotoinhibisi) (Widyaningrum dkk., 2013). Intensitas terendah yang terukur adalah 83 lux pada jam 20.00 WIB.

\subsection{Keadaan tanpa Cahaya}

Waktu pengambilan data dilakukan dari jam 08.00 WIB - 15.00 WIB. Hasil konsentrasi gas $\mathrm{O}_{2}$ yang di dapatkan pada lampu halogen 0 lux dapat dilihat pada Gambar 11. Fotobioreaktor mengalami penurunan konsentrasi gas $\mathrm{O}_{2}$ pada jam ke-3 dan jam ke-4. Hal ini membuktikan bahwa pada saat lama penyinaran tersebut proses fotosintesis tidak berjalan dengan lancar dikarenakan terjadinya pengurangan energi yang dibutuhkan pada saat proses fotosintesis pada lama penyinaran tersebut.

Konsentrasi gas $\mathrm{O}_{2}$ yang dihasilkan pada fotobioreaktor yang disuplai gas $\mathrm{CO}_{2}$ lebih rendah dibandingkan dengan tanpa pemberian gas $\mathrm{CO}_{2}$. Hal ini disebabkan karena pada keadaan gelap mikroalga tidak mampu melakukan proses fotosintesis secara maksimal sehingga pemberian gas $\mathrm{CO}_{2}$ pada mikroalga tidak mampu diserap oleh mikroalga untuk diproses menjadi $\mathrm{O}_{2}$. Hal ini menyebabkan pemberian gas $\mathrm{CO}_{2}$ menjadi emisi yang dapat mengurangi konsentrasi gas O2. Pada fotobioreaktor tanpa suplai gas $\mathrm{CO}_{2}$ tidak terjadi penambahan gas $\mathrm{CO}_{2}$ sehingga menyebabkan lebih banyak konsentrasi gas $\mathrm{O}_{2}$. Konsentrasi gas $\mathrm{O}_{2}$ tidak mencapai $20 \%$. 


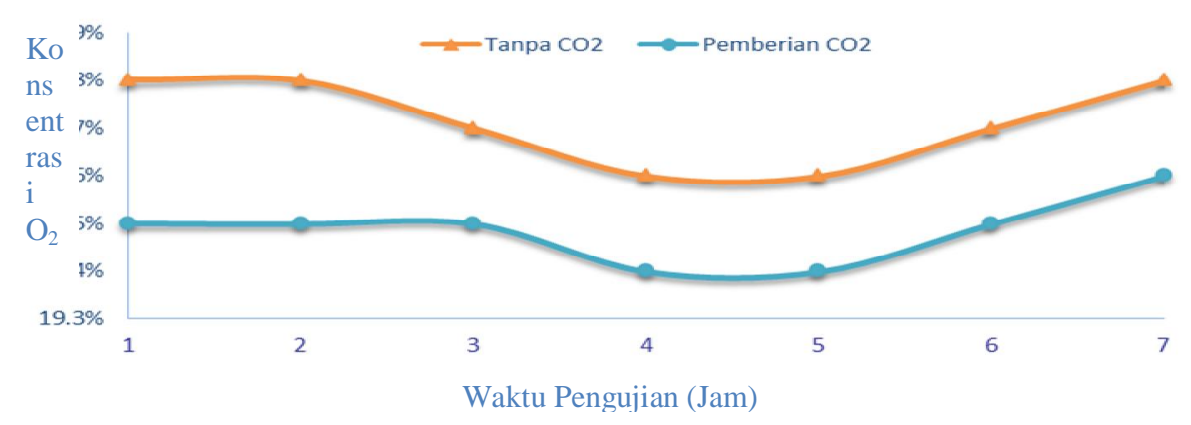

Gambar 11 Grafik konsentrasi gas $\mathrm{O}_{2}$ yang dihasilkan pada intensitas 0 lux

\section{KESIMPULAN}

Rancangan fotobioreaktor mikroalga Chlorella vugaris menggunakan lampu halogen dan LED Biru telah berhasil mengoptimalkan konsentrasi $\mathrm{O}_{2}$ dengan persentase di atas $20 \%$. Kedua sensor LM35 yang digunakan untuk kontrol temperatur pada fotobioreaktor telah berfungsi dengan baik dengan koefisien determinasi sebesar 0,9986 untuk sensor LM35 ke-1 dan 0,9947 untuk sensor LM35 ke-2. Perancangan alat kontrol temperatur telah berhasil mengontrol temperatur pada fotobioreaktor agar tetap pada rentang suhu $25-35{ }^{\circ} \mathrm{C}$. Konsentrasi gas $\mathrm{O}_{2}$ tertinggi adalah 21,7\% yang diperoleh dari fotobioreaktor lampu halogen 1000 lux dengan suplai gas $\mathrm{CO}_{2}$ pada jam ke-7 dan pada fotobioreaktor sumber cahaya matahari dengan suplai gas $\mathrm{CO}_{2}$ saat jam 15.00 WIB. Konsentrasi gas $\mathrm{O}_{2}$ pada lampu halogen 0 lux tidak sampai $20 \%$. Konsentrasi yang didapatkan berada pada rentang 19,4\%-19,8\%.

\section{DAFTAR PUSTAKA}

Andriyono, S., 2001, Pengaruh Periode Penyinaran Terhadap Pertumbuhan Isochrysis Galbana Klon Tahiti, Skripsi, IPB, Bogor. Hal $14-22$.

Bernard, O., Goncalves, A., Bensalleem, S., Lopes, F., Maia, S.R, 2016, Influence of Temperature On Chlorella Vulgaris Growth Andmortality Rates In A Photobioreactor, Journal of Alga Research, Department of Geosciences, Virginia Tech, Blacksburg, VA.

Chrismadha, T., Suryatini, D., Mardiati, Y., 2007, Respon Kultur Mikroalga Dalam Fotoreaktor Tegak Berpenyekat Terhadap Variasi Intensitas Cahaya, Jurnal Oseonologi dan Lirnnologi, Hal.245-256.USA, Hal. 352-359.

Daniyati, R., Yudoyono, G., Rubiyanto, A., 2012, Desain Closed Photobioreaktor Chlorella Vulgaris Sebagai Mitigasi CO2, Jurnal Sains dan Seni ITS, Vol.1, Jur.Fisika ITS, Hal $1-5$.

Hadiyanto, Samidjan, I., Kumoro, A.C., Silviana, 2012, Produksi Mikroalga Berbiomasa Tinggi dalam Bioreaktor Open Pond, Prosiding Seminar Nasional Teknik Kimia,Yogyakarta.

Kurnia, I., 2015, Optimasi Pertumbuhan Dan Hidrolisis Lignoselulosa Dari Mikroalga Chlorella vulgaris Untuk Meningkatkan Kadar Glukosa Sebagai Bahan Baku Bioetanol, Skripsi, Unand, Padang.

Nurhayati, A.D., Aryanti, E., Saharjo, B.H., 2010, Kandungan Emisi Gas Rumah Kaca Pada Kebakaran Hutan Rawa Gambut Di Pelalawan Riau, Jurnal Ilmu Pertanian Indonesia, Vol. 15 No.2, hal 78-82.

Pujiono, E.A., 2013, Pertumbuhan Tetraselmis Chuii Pada Medium Air Laut DenganIntensitas Cahaya, Lama Penyinaran Dan JumlahInokulan Yang Berbeda Pada SkalaLaboratorium, Skripsi, Universitas Jember, Jember.

Widyaningrum, N.F., Susilo, B., Hermanto, B.M., 2013, Studi Eksperimental Fotobioreaktor Photovoltaic Untuk Produksi Mikroalga (Nannochloropsis Oculata), Jurnal Bioproses Komoditas Tropis, Vol.1 No. 2, Jurusan Keteknikan Universitas Brawijaya, Hal 30-38.

Yuliandri, F., Utama, Y.D., Buchori, L., 2013, Biofiksasi $\mathrm{CO}_{2}$ Oleh mikroalga Spirullina Sp. Dalam Upaya Pemurnian Biogas, Jurnal Teknologi Kimia dan Industri, Vol.2 No.4, Jur. Teknik Kimia UNDIP, Hal. 125-131. 